\title{
Anti-racist school leadership: making 'race' count in leadership preparation and development
}

Paul Miller, University of Greenwich, London, UK

School leaders in England have a huge task to mediate factors in a school's environment (regulatory/legal and institutional). Rapid and sometimes conflicting policy agendas for improved performance have become a main preoccupation of school leaders as they jostle to keep their jobs as they wrestle to implement the latest government mandate. As a result, many school leaders to ignore, at best, or are unprepared for, at worse, how to deal with institutional impacts and challenges associated with unprecedented levels of migration, and race discrimination. This is compounded by school leaders' lack of understanding of, for example, personal and structural racism, and how these collude against attempts to build racially inclusive school environments.

Through an ecological model this paper argues that in spite of performativity pressures, school leaders should develop skills, attributes and knowledge in areas of curriculum diversity, recruitment and career progression, leading change for race diversity that (i) reflects the contexts within which they live and work, and that (ii) empowers them to more effectively serve their institutions. The paper asserts that 'anti-racist' training for school leaders should be central to ongoing professional development efforts, especially in multi-cultural, multiracial and multi-ethnic societies/educational environments.

KEYWORDS: Antiracist, school leaders, professional development, equity culture

\section{Race, ethnicity and school leadership: a historical and emergent context}

Many schools and school leaders in England, and elsewhere, are confronted, almost daily, with issues to do with 'race' involving their staff and students. Unfortunately, many of these school leaders, both those who are very experienced and others less experienced, struggle to adequately and successfully address and engage with the range of race-related concerns they/their schools face. In an increasingly polarised global and British societies, racism and race discrimination have nearly become normalised - leaving educational institutions, and many of those who study and work in them, exposed to the rhetoric and practice of racism. Anzaldua $(\underline{1990})$ notes that 'racism is a slippery subject, one which evades confrontation, yet one which overshadows every 
aspect of our lives' (Anzaldua 1990, p. xix). This observation points to the pervasive nature of racism, and its near inescapable characteristic and presence. Nevertheless, "what has emerged over the last decade or so is an acknowledgment of the complexities of racism' (Aveling 2007, p. 69); and the realisation that racism is 'not a static, fixed, or coherent set of beliefs that uniformly influences the way individuals think and behave regardless of context' (Connolly 1996, p. 174). Notwithstanding, Macpherson (1999) in the 'Stephen Lawrence Inquiry Report' provides that, racism is, 'Conduct or words or practices which advantage or disadvantage people because of their colour, culture or ethnic origin. In its more subtle form, it is as damaging as in its overt form' (p. 41). Consistent with the pervasive and near inescapable character of racism,

[I]t will therefore be important that all staff, including recently recruited staff, are aware of procedures to deal with racist incidents and support to tackle racial bias and stereotyping. Strong leadership from the school's governors and the school's senior management team on the unacceptability of racism will give staff the confidence to manage incidents well. (Lancashire County Council 2007, p. 6)

Racism extends beyond individual expressions of prejudice and 'includes systematic, structural, unequal relations of power' (Raby 2004, p. 380); and could also be viewed as

the result of a complex interplay of individual attitudes, social values and institutional practices. It is expressed in the actions of individuals and institutions and is promoted in the ideology of popular culture. It changes its form in response to social change .(Australia - Department of Education and Training n.d., p. 1)

Thus, 'it is no longer useful ... to speak of racism as if it were a homogeneous phenomenon' (Castles 1996, p. 18) and an understanding of its complexities becomes essential to recognising and tackling it in its various guises. Conceptual differences around racism aside, a racist is typically seen as someone who discriminates based on 'race' or skin colour; or someone who, according to 'common sense,' is 'bad, mad or misinformed, or even stupid' (Pettman 1992, p. 56).

Racism can take many forms. For example:

- Personal: related to private beliefs, prejudices, and ideas that individuals have about the superiority of whites and the inferiority of non-whites. 
-Interpersonal: occurring between individuals. It occurs when the private beliefs of individuals affect or influence their interactions with others.

-Institutional: related to unfair treatment, policies and practices, inequitable opportunities and impacts within organisations and institutions, based on race, which routinely produce unequal outcomes for whites and non-whites.

-Structural: related to a system in which policies, institutional practices, cultural representations, and other norms work in various, often reinforcing ways to perpetuate racial group inequality. It involves the cumulative and compounding effects of several factors including the history, culture, ideology, and interactions of institutions and policies that systematically privilege white people over non-whites.

This paper acknowledges the different levels of racism, although its main focus will be on upskilling and educating school leaders to tackle institutional racism. This is not to say however that school leaders do not have a duty of care to tackle all forms of racism, including personal racism. As noted by Yamato (1990), 'racism is pervasive to the point that we take many of its manifestations for granted, believing "that's life" (p.20), and leaving many of its assumptions and manifestations unchecked or unquestioned (Hollinsworth 1998). This paper is based on three main questions: (i) Why does "race" matter in leadership preparation and development? (ii) What content on "race" could be included in leadership preparation and development? (iii) How could "race" be included in leadership preparation and development? Before I attempt to answer these questions, I will provide an introduction to the context of race/racism and educational leadership in England.

\section{Race, ethnicity and school leadership in England}

There is a dearth of literature on what educational and/or other institutions do to tackle institutionalised racism - with much of the available literature focused on structural and other factors that both foster and embed race discrimination/racism (Miller 2019a). In its simplest sense, an educational institution is a microcosm of society, not only reflecting its diversity of peoples but also its diversity of values and epistemologies. Consequently, the routinisation of practices and the development of cultures therein are crucial to how individuals and groups inhabit and experience these institutions. In the main, England (and by extension the UK) can be considered an inclusive country. However, beneath the surface, the practices and cultures of many institutions, within and outside education, are anything but inclusive. What goes 
on in educational institutions is important for several reasons, not least because educational institutions are melting pots of diversity and difference, and thus mirrors of society, but because many of society's values are simultaneously tested out, challenged, shaped, re-affirmed and embedded through and within the social discourses and practices occurring within these (and other) institutions. Consequently, educational institutions have a significant role and responsibility to tackle all forms of prejudice through its curricular, human resource policies and other operational practices and systems.

Bell (2004) notes that racism is a reality. Miller (2019b, p. 2) also notes that 'racism in England's education system is a reality - a reality played out in different ways, affecting students and staff in multiple ways and influencing their experience of, and interaction with/in the education system' (p. 2). This reality is juxtaposed against England's '... deep sensitivity to ... ethnic and cultural difference' (Phillips 2016, p. 1), which arguably provides fertile ground for augmenting racist attitudes and cultures, aided by leadership inaction (Miller 2019c); lack of monitoring of institutional practices by government (Miller 2016), and a weak legislative framework (Miller 2019a). Thus, England's (and by extension the UK's) deep sensitivity to ethnic and cultural difference underpins and reifies deep levels of mistrust for 'the other', often manifested in how 'the other' is treated, and what opportunities are available to 'the other'. Put differently, despite espoused values of equality, diversity and inclusion, many of England's educational institutions, have created, fostered and/or reinforced systems of 'in group' and 'out group' along racial lines; systems which privilege the experience and worth of some over others (Miller 2019b).

On their own, staff of BAME heritage are incapable of successfully resolving these tensions due to resistance (McNamara et al. 2009) or suspicion (Bhopal and Jackson 2013) or both, and due to the restrictive nature of BAME capital (Miller 2016). Notwithstanding these tensions, it should be emphasised that educational leaders wield significant power, and are

... uniquely placed to influence staff, students and other stakeholders in ways that help raise their awareness of and attention to issues of racism/race discrimination, and to helping and enabling them to tackle race and other forms of discrimination, and to promoting, building and sustaining educational institutions in ways that positively influence all who study and work therein. (Miller 2019b, p. 2)

Since 'leaders/leadership can be a powerful antidote to race inequality and discrimination in organisations' (Miller 2019b, p. 2), it is appropriate that professional development efforts focus attention on an area that so far has not 
been satisfactorily addressed, and an area not systematically built into training and/or development activities. This paper contends that school leaders in England need to develop an 'anti-racist' language and practice, based on appropriate skills, attributes and knowledge geared towards enabling and empowering them to (better) tackle institutional racism/race discrimination.

\section{Students and teachers of BAME heritage in England}

As of January 2017, there were 8.67 million pupils enrolled in state-funded and independent schools in England. Of the 4,689,660 at primary schools, circa $32.1 \%(1,505,381)$ are of BAME heritage; and of the 3,223,090 at secondary schools, circa $29.1 \%(937,919)$ are of BAME heritage (DfE, 2017). Patterns of variation exist within the overall data, with some schools in London, for example, having up to $70 \%$ BME students enrolled, although staffing profiles do not always reflect the ethnic diversity of the student body. Furthermore, the proportion of students of BAME heritage has risen steadily since 2006, and account for circa $66.3 \%$ of the increase in primary school students between 2016 and 2017.

According to the latest school workforce data available from the Department for Education (DfE, 2018), as at January 2020, there were approximately 453,000 teachers in the state sector in England. This number is broken down as follows: White: $85.9 \%$ (or 399,300) are White-British, 3.9\% (or 18,000) are from 'Other White' backgrounds, $1.6 \%$ (or 7,300) are White-Irish; Asian: $1.9 \%$ (or 8,900) are Indian, 1.2\% (or 5,500) are Pakistani, 0.6 (or 2,700) are Bangladeshi, 0.7 (or 3,100 ) are 'Asian other'; Black: 1.0\% (or 4,800) Black Caribbean, $0.9 \%$ (or $4,000)$ are Black African, $0.3 \%(1,500)$ are 'Black other'; Mixed: Mixed White/Asian $(0.3 \%$ or 1,600$)$, Mixed Black/African $(0.1 \%$ or 600$)$, Mixed Black/Caribbean ( $0.4 \%$ or 1,700$)$, Mixed Other ( $0.5 \%$ or 2.400$)$; Chinese: 0.2 (or 800 ), 'Any other' (0.6\% or 2,700 ); Unknown: $7.79 \%$ (or 35,300$)$. Put differently, there are approximately White-British 399,300 teachers (85.9\%), 35,000 teachers $(7.79 \%)$ whose ethnicity is unknown, and 18,400 teachers $(6.31 \%)$ of BAME heritage. Furthermore, there are approximately 22,400 principals or headteachers: $92.9 \%$ (or 20,809) are White-British, 1,200 (or $5.3 \%$ ) whose ethnicity is unknown, and 391 (or 1.7\%) of BAME heritage (DfE, 2020).

\section{Institutional interaction and students and staff of BAME heritage}

From the data in the previous section, there are millions of students and thousands of teachers of BAME heritage within England's education system. 
For many of these students and staff however, their experience of their institution is highly fraught. Camacho Felix (2019) found that the experience of students of BAME heritage can be described as one of, 'A Lack of Belonging; A Loss of Confidence and A Feeling of Neglect' (p. 5). Demie (2003) also found four main school-related factors that contribute to how students of BAME heritage experience their school organisations: “... stereotyping; teachers' low expectations; exclusions and Headteachers' poor leadership on equality issues" (p. 243). Low teacher expectation is strongly correlated to low attainment amongst students of BAME heritage (Gillborn 1995, Curtis 2008). Low teacher expectation is believed to be influenced by racism (Gillborn 1996, Gillborn and Youdell 2000, Strand 2015). Strand (2012) found students of BAME heritage were systematically 'encouraged' to take foundation courses, which has contributed to achievement gaps. He concluded that institutional racism and low teacher expectations are two reasons why they were not entered for top-tier exams.

Another factor influencing the attainment of students of BAME heritage is their exclusion from learning opportunities and from school. For example, students of BAME heritage are most likely to be excluded from school (DfE, 2016) and represent the most excluded group of pupils (Gillborn and Youdell 2000, DfE 2016). Furthermore, they have rates of permanent exclusion nearly three times that of the student population (DfE 2016). The failure of the curriculum to adequately cater to the needs of students from minority ethnic backgrounds (Macpherson 1999, Strand 2015) has also been cited as a factor in their overall educational experience. Furthermore, students of BAME heritage are subjected to institutional racism in British schools through, inter alia, teachers' 'conscious or unconscious stereotypes and assumptions about minority groups [which] can impact negatively on pupils' achievements' (Maylor et al. 2009, p. 25); which can dramatically undermine their chances of academic success (Curtis $\underline{2008}$, Demie and Mclean 2017). On their own, or together, these factors can perpetuate low attainment and engagement. Importantly, they provide us an insight into the experience of students of BAME heritage educational institutions.

Overall, the experiences of teachers of BAME heritage in their institutions are broadly consistent with how students of BAME heritage experience their institutions. Although possessing similar career aspirations, ambitions and qualifications as White teachers, it has been found that they are far more likely to be disciplined; to face criticism from colleagues and parents (McNamara et al. 2009); to experience occupational segregation (Miller 2019a); and be passed over for promotion (SecEd, 2015, Miller 2016). Furthermore, trainee teachers of BAME heritage are least likely to complete their training (Pells 2017), due to lack of support (Lander 2011); racism (Callender 2019) and feelings of ethnic 
and cultural isolation (Miller 2020). The experience of teachers of BAME heritage in educational institutions is thus a deeply fraught issue - which has implications for their recruitment, development, retention and progression.

Despite the existence of equality legislation, and despite campaigns in the public domain, many educational institutions have done very little to improve the experience of students and staff of BAME heritage. Miller (2018) observes a zero-sum game where, instead of facing up to racism within their institutions, some educational leaders opt to prioritise performance agendas at the expense of enforcing the 'race' equity agenda, often seeing one thing as being incompatible with the other. On Furthermore, the Equality Challenge Unit (2011) reported that where some institutions have embarked on initiatives with race, where these have not been led and managed from the top, either directly or indirectly, they have experienced very little to no positive result. Accordingly, the effort and response of educational institutions to tackling race discrimination in their midst have been seen as 'lacking commitment to change' (Ahmed 2007, p. 236); 'light touch' (Miller 2016, p. 218); and not having '... the ... resources and authority for the initiative ...' (ECU 2011, pp. 46-47).

\section{Why does 'race' matter in leadership preparation and development?}

Tackling racism/race discrimination in schools and other educational institutions is not a quick fix; nor is it a single linear process. With increased globalisation and migration, the job of tackling racism/race discrimination is one that educational leaders, irrespective of school location and size, and irrespective of country, can expect to grapple with. For the most part, school leaders are unprepared for the challenges of tackling and achieving racial equity, and are uncomfortable with calling out racism (Aveling 2007, McMahon 2007, Ryan 2012); this, because, school leadership preparation and development programmes have traditionally focused on management skills (Fullan 1999) and have not given adequate attention either to the need for or skills to mediate the increasing diversity that has come to characterise many schools/modern day schooling (Henze 2000). Thus, Greene (2007) notes, 'Addressing structural racism is one of the toughest jobs that any leader can face ....' (p. 10). The tension among individual leaders and educational systems and educational institutions that place a subordinate value on tackling racism/race discrimination presents a real and certain threat to achieving race equality. As Greene (2007) notes,

In institutions where there is little or no consciousness of racial bias, the social culture of unconscious racism will influence basic 
policies and practices. Unfortunately, even in institutions that have

a fairly high degree of awareness of race bias, unconscious or unexamined aspects of the institution's social culture can unintentionally reinforce dynamics that continue to privilege people with white skin. (p.11)

Accordingly, ensuring school leaders have the appropriate language, skills and knowledge to push back against and successfully tackle racism/race discrimination is important and beneficial to the individual leader, the institutions they lead, and the education system and to society in which they live and work. The Coalition for Equity and Rights (n.d.), found that:

[T]raining opportunities are a great way to build the capacity of the school to address incidents of racist bullying and create inclusive learning environments. This creates a consistency in approach and improves competence and confidence in this area. (CRER/respectme, nd, p.11)

Drawing on Henze (2000), Gooden (2012); Brooks (2012); Brooks and JeanMarie (2007); Theoharis and Brooks (2012); Brooks and Watson (2018), and Miller (2019), several reasons underpinning the importance of school leaders understanding of racism, and developing a language and practice of 'antiracism' are suggested below:

1. School leaders have the power to influence race relations positively: Schools and other educational institutions play a complex and uneasy role in changing race relations, sometimes hindering and fostering positive relations, often at the same time (Henze 2000). Despite performativity constraints and other barriers, committed school leaders find ways to make race central to the work of their personal practice and the life of their schools (Miller 2019b).

2. School leaders have the power to establish and influence cultures: Each school organisation is unique, but what the school becomes noted and known for is largely down to the ability of the leader to set goals and parameters and work towards them. As noted by Miller (2018), leadership shapes culture, and culture shapes leadership. This truism is important, but given the uniqueness of each institution, helping school and other educational leaders develop their ability to read their institution is a crucial element of influencing and leading change.

3. School leaders can help reframe problems, ameliorate conflicts and inform strategies: Issues to do with 'race' tend to evoke and 
provoke a plethora of emotions and responses. When leaders understand what racism is, and its effects, they are in a much better position to directly and indirectly mediate, tackle race related infractions, and resource, lead, support and demand actions. Furthermore, being knowledgeable about racism and its effects enable the leader to "reframe the problem, recognising overt conflict as a "symptom" and underlying tensions and root causes as the "illness"” (Henze 2000, p. 2).

\section{School leaders can secure buy-in and create an institutional} multiplier effect: Many people are concerned about racism in educational institutions. Some do nothing about it because they do not see it as their job; and others want to do something but are not sure what they can do. On the back of highlighting the extent of the problem or issue, the school/educational leader can cascade the knowledge of what's required and how this could be approach to others (teachers, parents, students, community members, school boards, etc.). This inclusive and collective approach to tackling the difficult issue of institutional racism/race discrimination provides opportunities for teachers, students and others to 'own the issue', thereby creating a greater likelihood of interventions being successful and sustained (Miller 2019b).

\section{Schools leaders can more easily influence practice outside their} institutions: It is easy to pretend that a problem does not exist, or to allow it to slip down the priority list, when one does not know how to tackle it. When school leaders understand racism, and its effects; many will want to attempt to tackle this, not only within their organisation but also beyond recognising the interlocking relationship between what happens in educational institutions and what happens in society. School leaders learning together, reflecting together, strategising together to tackle racism/race discrimination can improve the quality of institutional interventions well beyond their own institutions and they can support each other (which can lead) to greater levels of accountability.

Successfully tackling institutional racism/race discrimination requires huge investments in time, the personal commitment of leaders, and human and financial resources. The Dismantling Racism project (2019) notes,

The process of Dismantling Racism is not just about individuals changing our behaviour and ways of thinking. This important work must in turn trigger a commitment to dismantling racism in 
organizations in order to provide us to move effective and accountable racial justice organizing. (p.56)

Likewise, Miller (2019b) asserted,

[D]oing race equality is serious business, and doing race equality in schools or educational institutions is serious business that requires courage and the moral use of power that extends beyond sympathising to taking actions. (p. 17)

For school leaders and educational institutions to dismantle institutional racism, a pre-requisite is developing the courage to tackle it, which itself follows from an understanding of the nature of racism and its effects.

\section{What content on 'race' could be included in leadership preparation and development?}

There is no one size fits all to tackling institutional racism and attempts to tackle racism must acknowledge contextual and other complexities. This was clearly articulated by the Dismantling Racism project (2019) which proposed,

There is no cookie cutter approach to anti-racist organizational development. The road to anti-racist organizational development is necessarily impacted by the size, structure, mission, constituency and geographic location of an organization. (p. 56)

Nevertheless, and despite the unavailability of a one size fits all approach to tackling institutional racism, and despite contextual differences, it is crucial all school leaders are provided with appropriate and adequate content knowledge that will enable them to (i) talk confidently about race/racism; (ii) respond to changing student and teacher demographics; (iii) cater adequately to the learning and development needs of students; (iv) tackle discrimination in the recruitment, development and progression of staff; and (v) build racially inclusive institutional processes, structures and cultures. These five areas are by no means exhaustive, and each area has potential to be a separate module. These are summarised below:

i. Learning to talk confidently about race/racism: This important area acknowledges that to tackle racism in any form, people need to get comfortable talking about it - drawing on a language register that is shared and/or understood by all. Understanding racism, 'moves beyond a focus on the symptoms of racism to an understanding of what racism is, where it comes from, how it functions, why it 
persists, and how it can be undone' (Greene 2007, p. 10).

Furthermore, understanding racism provides opportunities to develop a language around it and its effects (e.g. discrimination, microaggression etc.). With this knowledge, school leaders are in a better position to recognise individual acts of racism/race discrimination, institutional racism and structural racism, and are in a much better position to share their knowledge with others around them (students, staff, governors, donors, benefactors) in order to create institutionalwide awareness and to define the parameters of institutional-wide practice.

ii. Who is in my school? Respond to changing student and teacher demographics: This area reflects the fact that globalisation and migration are recalibrating the physical, psychological and cultural aspects of school/education. Far from leaders simply knowing that their institutions are changing, they need to know the students and staff make up, so their school is representative of its local community and of society. Accordingly, leaders need to immerse themselves in data concerning staff and students. For example, they should know the ethnic make-up of staff and students, the languages spoken by staff and students, the gender balance among staff and students, and their cultural references. In particular to students, they need to also know their socio-economic profile, and in particular to staff, they also need to know paygrade, job role, years in job role and contract type. Importantly, school/educational leaders need to know why it is important for them to know these things, and how this knowledge can assist their decision-making. In the context of debates on racism/race discrimination, not only is this area of knowledge common-sense, it is also about recognition, which can be an enabling factor in how students learn and in how staff and students make sense of and respond to their school environment. Miller (2019b) provides examples of school leaders proactively working with professional teaching associations to (i) recruit teachers of BAME heritage to better reflect and serve the needs of their student population, and, (ii) actively work with teachers and local school community organisations to embrace and demonstrate an awareness and appreciation for the traditions and cultures that reflect the lived experience of staff and students present at school.

iii. Whose curriculum? Catering to the learning and development needs of all students: This important area has been the subject of much discussion in the last decade. Although a school's ability to do this is complicated by several constraints within (staffing, time 
available, etc.) and outside a school (pre-set national curriculum, government policy, etc.), delivering a curriculum that caters to the learning and developmental needs of all students is crucial to their development and thriving as independent human beings. Providing a 'qualitatively different educational experience' (Miller 2012, p. 9) to students of BAME heritage, that reflects their needs, histories, cultures is not merely about representation and recognition, but also about respect. School/educational leaders need to understand what respect means in this context. That is, respect for their cultures, ethnicities, their right to be seen and heard in everyday educational discourses. Where this kind of educational experience is not available to students of minority ethnic backgrounds, educational institutions risk alienating students and staff from these backgrounds, which in turn can lead to resentment which, by extension can undermine the confidence of staff and students in their institutions and in the ability of its leaders to deliver inclusive educational content for all and to demonstrate inclusive curriculum leadership.

iv. Tackling discrimination in the recruitment, development, retention and progression of staff: This crucial area acknowledges the complexities of talent management in general (Lewis and Heckman 2006, Christensen and Rog 2008) and in education in particular (Haque and Elliott 2016). By understanding the value of staff of minority ethnic heritage in their schools, leaders can address gaps in their recruitment, development, retention and progression. They learn about bias, and how this manifest in everyday decisionmaking around staff; and about how to limit bias infiltrating decisions about staffing, etc. Furthermore, supporting educational leaders to work effectively with 'others' to improve BAME teacher recruitment will help them develop essential skills and networks, including working with a school's local community to boost recruitment from that community, and with teacher networks (e.g. BAME teacher networks), teaching organisations, teaching unions, ITE providers, etc., to improve teacher recruitment. Development, retention and progression are at the heart of debates on talent management. In the context of institutional racism/race discrimination, these are at the heart of an 'ongoing struggle' for 'legitimacy' and 'enabling' among teachers of BAME heritage (Miller 2016, p. 1). School/educational leaders need support in thinking through institutional factors, personal conundrums, as well as administrative roles and responsibilities in creating an enabling environment for all staff - regardless of race/ethnicity. 


\section{v. Building racially inclusive institutional processes, structures and}

cultures: This important area revolves around 'creating change', and 'making change sustainable'. This includes looking at existing processes, for example in the: (i) attraction, recruitment and selection of staff; (ii) reward, recognition, professional development and progression of staff; (iii) tracking of complaints against staff and students of BAME heritage; (iv) tracking of disciplinary measures taken against staff and students of BAME heritage; (v) development and/or review of policy around inclusion/anti-racism; (vi) institutionwide action-planning and monitoring of BAME student attainment; (vii) annual monitoring of agreed actions and targets related to staff and students of BAME heritage. This also involves working with a range of stakeholders, both internal and external to the institution, and including staff and students of BAME heritage to contribute to the development, implementation, monitoring and evaluation of interventions.

As mentioned above, these five areas in no way reflect an exhaustive and/or comprehensive body of knowledge for what could be involved in developing 'race conscious' or anti-racist leaders. However, they provide a starting point, since undoing racism requires working to a 'common language' with an 'antiracist organizational plan' (Greene 2007, p. 10); and the development of a '... comprehensive understanding of how racism and oppression operate within an organization's own walls' (Dismantling Racism project, p. 56). Since, institutions, like individuals can evolve to become antiracist, successful institutional change must, simultaneously, include individual and institutional components, working together and in sync.

\section{How could 'race' be included in leadership preparation and development?}

Tackling institutional racism/race discrimination is not an easy task, and requires courageous leadership (Soyei 2011, Miller 2019b). Nevertheless, to improve the likelihood of success, courageous leadership itself should manifest from a set of a priori knowledge and skills. In other words, in the same way school leaders need to know about curriculum and instruction, they also need to know about racism and how this impacts staff, students and the institution as a whole. Accordingly, they must also be in a position to work with staff, students and others within and outside a school, to create the conditions for improvement. School leaders set the tone for their schools, and they can therefore influence, if not define its overarching ethos. Put differently, it is virtually impossible to (re)-culture a school without first, equipping the leaders 
to see that tackling institutional and other forms of racism is not an 'add on' but part of its 'core business', and second, assisting them in combining their skills and knowledge to work with, and motivate others in building and ensuring cultures of equity for all.

However, there is no single way to equip school leaders with the knowledge and skills needed to tackle institutional and other forms of racism which may manifest at school. Darling-Hammond et al. (2007), and Soyei (2011) found that although in-service programmes catered to the curriculum and instructional needs of school leaders, this did not include content on understanding racism and/or how to tackle racism. Furthermore, a Public Agenda Report (2008) reported that principals suggested their colleagues were more helpful in their preparation for administration than graduate courses (NEA Policy Brief 2008). These findings would suggest the preparation and development of school leaders' 'race consciousness' are neglected. Although not discounting university training in educational administration and/or leadership, 'equally important is the training and support school leaders receive after they're hired' (Mitgang and Gill 2012, p. 24). From a survey of almost 1,000 principals, Whitmire (2012) found that over half feel they would be more effective with ongoing development. Fullan (2009) reasons that leaders will need job-embedded learning, system-embedded learning, and organisationally-embedded learning which focuses on 'shared learning' in the context in which they work. Furthermore, Allio (2006) also acknowledges,

Men and women become leaders by practice, by performing deliberate acts of leadership. Evidence suggests that the most effective leadership programs will focus on building selfknowledge and skills in rhetoric and critical thinking.

Specifically, regarding content on 'race', Greene (2007) found that 'workshops offered opportunities for managers to practice race dialogues, learn new techniques, and ask questions as well as learn from each other' (Greene, p.11). Greene also observed, 'it became clear that our managers needed specialized training in order to be able to fully integrate anti-racist principles into the core of their management' (p.11). The illustrations above are a timely reminder that there can be no one size fits all approach to the preparation and development of school leaders, and there can certainly be no one size fits all approach in helping them to develop as anti-racist leaders. Accordingly, and drawing on the range of professional development approaches highlighted above, this paper suggests that an ecological model of professional development is needed for school leaders to support them in developing a language and practice of race consciousness. This is presented below. 
Attributes (be): These are related to an individual's core self: personality, values and beliefs. Professional development opportunities should get school leaders to reflect on who they are as individuals, as leaders, and on what matters to them as individuals and as leaders. There may be times when these may be out of sync, and it is important that school leaders not only reflect on why aspects of their core selves may be out of sync but also how to get them back in sync. For example, is institutional racism an important issue or concern for school leaders? How is this concern manifested? Do they as leaders see it as their duty/responsibility to tackle institutional racism? How do they go about tackling institutional racism/race discrimination? Underlying these tensions is the question of a leader's willingness to tackle problems, exert their influence, and advance the overall human good and value of the organisation.

Figure 1. Ecological Model of Professional Development.

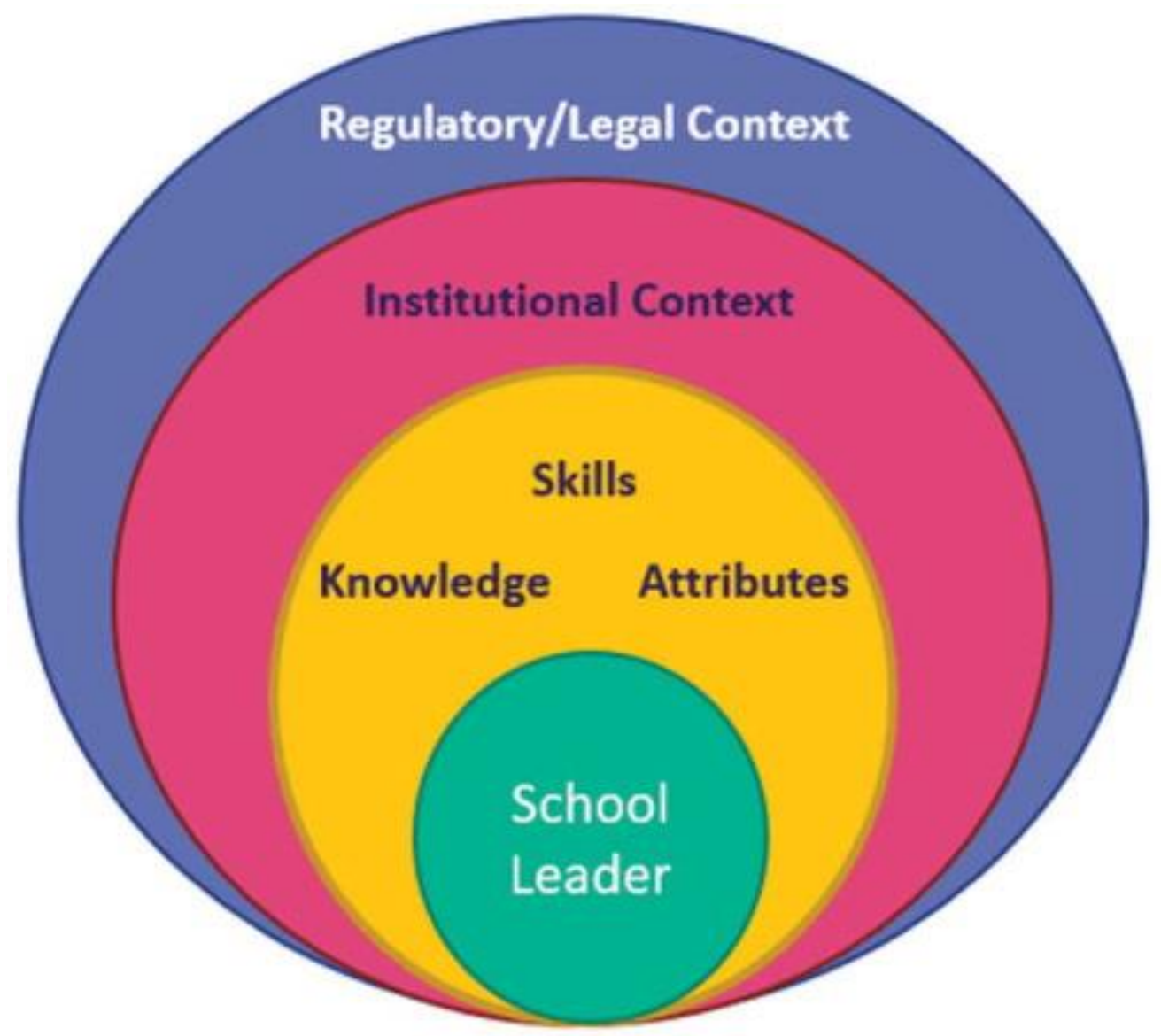

Display full size

Skills (do): Helping school leaders to undertake a skills audit is as important as unearthing aspects that need development. School leaders need several key skills to effectively manage the complexity of their roles. For example: (i) problem-solving skills; are school leaders equipped to solve complex institutional problems such as institutional racism and race discrimination? How can they develop these skills? Are they prepared to seek out and develop these 
skills? (ii) social judgement skills; are school leaders sufficiently equipped to read individuals and institutions? Being able to read the individuals within an organisation, and the mood of the organisation is key to tackling institutional and other forms of racism. (iii) professional skills; are school leaders sufficiently networked within and outside their institution? Can they leverage support and respect for change initiatives within and outside their institution? How can they increase their visibility on an issue without undermining their position?

Knowledge (know): Are school leaders sufficiently aware of the extent and forms of race discrimination (and other challenges) faced by staff and students within the institution? Are they aware of how widespread the issues are? Do they know the impact of these challenges on individuals, groups, families? Have they considered the impact of these challenges/occurrences on the school's reputation, sustainability, etc.? What accountability mechanisms are in place for those in breach of rules and regulations? What support or redress is available for victims of race discrimination? These provide an illustrative list of questions representing the complexity of problem-solving around institutional racism.

Context (where, when): Are there issues, processes and people in a school's context that promote institutional racism? Are these issues historical or contemporary? How can these issues be tackled? What resource (financial, human, etc.) is required and can these be found internally? What would it mean for the institution if these issues were not tackled? Do schools have legal and regulatory duties for tackling institutional racism/race discrimination? What are these duties? Is there a monitoring, reporting and public accountability duty? Do schools face consequences when legal duties are not enforced?

This ecological model is concerned with equipping school leaders with jobembedded learning, system-embedded learning, and organisationally embedded learning (Fullan 2009) which recognises the uniqueness of context, and how school leaders engage with that context. As provided by Greene (2007),

The core of anti-racist work is to seek to recognize institutional bias and to make structural changes that are supported by policies and procedures that are accountable with outcomes of equity. Leaders, managers and supervisors must be taught to recognize that contemporary forms of racism exist and become familiar with the various forms that it takes in the lives of all staff and clients. They must become vigilant in learning and identifying what those issues are and how they are perpetuated in the organization's policies, practices and procedures. The goal of anti-racist work is to widen the circle of power and opportunity. The leadership must be taught how to help white staff as well as staff of color to better understand 
how systemic racism works and impacts all staff and clients and be prepared to offer strategies and support for systemic change. (p.

11)

Taking these observations into account, it is acknowledged that this ecological model is contingent upon the individual school leader making a commitment, and acting on/out this commitment to tackling institutional racism/race discrimination; and in doing so, they will devise ways to lead and support their school towards a language and a practice of anti-racism; a language and a practice that starts with and embodies their personal values and beliefs but also draws from a wider set of values and beliefs as applicable.

\section{Resolving the future? Tackling the challenges to building a race equity culture}

Whilst several educational leaders across the sector, from nursery to university, express a desire to build a culture of race equity within their institutions, several often face challenges in how to go about this. Suarez (2018, p. 2) provides examples of three common challenges:

- Uncertainty on where and how to start: White leaders may fear saying or doing the wrong thing, or being perceived as blind towards the experiences of staff of BAME heritage. Similarly, leaders of BAME heritage, who have otherwise succeeded within white dominant cultures, may fear being ignored or dismissed for being too 'passionate' if they raise concerns about inequity.

- Lack of awareness of personal biases: Leaders of organisations seeking to close the wealth gap or otherwise 'level the playing field' may naturally view themselves as anti-racist. Even committed leaders (including those of BAME heritage) can be unaware of the ways they contribute to or perpetuate structural racism.

- Impatience with the work required to build a culture of race equity. Race equity work is serious business and it needs to go beyond the transactional, e.g.: increased representation and developing institutional policies around race diversity and inclusion, shifts in institutional practices and cultures. This requires accepting that this work and process takes time, is not straightforward, and requires embracing the challenges and tensions associated with this work.To compound the three challenges identified by Suarez above, I argue here that there are three categories (five types) of leaders, and their position on this typology is a response to tackling racism in their 
institutions, and an indication of the levels and types of support they may require. See Table 1: Types of (educational) leaders

\section{Table 1. Descriptive statistics.}

\section{CSVDisplay Table}

Bell (2004) notes that racism is a reality. Miller (2019b) also notes racism in education in England is a reality. Brooks and Jean-Marie (2007) further note that school leaders both influence and are influenced by racism. Thus, to stand a chance of creating and sustaining an antiracist institution, school leaders first comprehend the levels of racism in society and how these influence them; second, they need to understand their own roles in perpetuating structural and interpersonal racism; and third, they need to identify and commit resources to addressing these. As provided by Greene (2007) highlights, 'Structural racism requires institutional support and cultural nurturing' (p. 11) - and school leaders should not be complicit in this, nor can they appear or afford to be. Drawing on Suarez (2018, p. 203), and to increase the likelihood of being successful in tackling institutional and other forms of racism/race discrimination, school leaders should:

- Learn the history and context of structural racism in England, and how it has affected people of BAME heritage;

- Listen to the lived experiences of people of BAME heritage within their institutions, without placing the emotional burden of justifying the validity of those experiences on them;

- Reflect on the role that leaders and their institutions play in perpetuating structural racism and dominant culture, which is an organisational culture influenced by the leadership, management, and development of white men and women;

-Examine the effects of implicit bias on disciplinary or related activities, recruitment and promotion, professional development, team power dynamics, and other critical programmes, management, funding, and operation decisions;

- Consider the messages, both implicit and explicit, that leaders and leadership styles shaped by dominant culture send to staff, communities, and stakeholders;

- Define roles and goals around race equity; 
- Fund race equity initiatives so that resources, including consultants, training, and one-on-one coaching, are available to grow staff capacity.

Anti-racist school leadership requires a nuanced approach grounded in an understanding of the history and context of structural racism, of personal racism and of the peoples affected by and those perpetrating acts of racism. Although each institution's journey is unique, Suarez $(2018$, p. 4) propose that each must undergo three stages of change, collectively described as the Race Equity Cycle:

-Awake: increased race diversity in organisations; focused on representation;

-Woke: internal change in behaviours, policies, and practices; equipping people to talk about race; focus on deeper inclusion and creating space so that everyone is comfortable sharing their experiences;

-Work: unstinting application of a race equity lens to examine an institution's programmes, practices and processes.

Crucial to creating an institution that is 'woke' or demonstrably race-conscious in language and practice are leaders who commit to their development in words and deeds and in the development of staff and students and everyone in the school community.

\section{Conclusions}

Anti-racist school leadership starts with making 'race' count in leadership preparation and development. Developing a race-conscious language and practice as a leader is not a linear activity, nor is it a one size fits all activity. The uniqueness of context: environmental and institutional must be recognised as a lever in a leader's ability to influence change and the pace at which change occurs. Through an ecological model, each leader develops an appropriate set of attributes, skills and knowledge which, although influenced by the particularities of each school's context, are enacted through a sense of personal agency. Thus, developing a language of race consciousness will not itself lead to a practice of race consciousness and inclusion if the school leader does not want to, or otherwise feels incapable of enacting such a practice. Despite the approach to preparation and/or professional development, developing a language and a practice of race consciousness or race equity culture therefore starts with and relies upon the individual school leader for its viability and sustainability. 


\section{Disclosure statement}

No potential conflict of interest was reported by the author.

\section{References}

1. Ahmed, S. , 2007. You end up doing the document rather than doing the doing: diversity, race equality and the politics of documentation . Ethnic and racial studies , 30 (4), 590-609. doi:10.1080/01419870701356015.

2. Allio, R.J., 2006. Leadership development: teaching versus learning . Emerald Group Publishing Limited.

3. Anzaldua, G. , Ed., 1990. Making face, making soul, Haciendo Caras: creative and critical perspectives by women of colour. San Francisco: Aunt Lute Foundation Books.

4. Aveling, N. , 2007. Anti-racism in schools: a question of leadership? Discourse: studies in the cultural politics of education , 28 (1), 6985. doi:10.1080/01596300601073630.

5. Bell, D. , 2004. Silent covenants: brown v. board of education and the unfulfilled hopes for racial reform . Oxford: Oxford University Press.

6. Bhopal, K. and Jackson, J. , 2013. The experiences of Black and minority ethnic academics: multiple identities and career progression. Southampton: University of Southampton.

7. Brooks, J. and Watson, T. , 2018. School leadership and racism: an ecological perspective. Urban education , 54 (5), 1-25.

8. Brooks, J.S., 2012. Black school, White school: racism and educational (mis)leadership. New York, NY: Teachers College Press.

9. Brooks, J.S. and Jean-Marie, G. , 2007. Black leadership, White leadership: race and race relations in an urban high school. Journal of educational administration , 45 (6), 756-768. doi:10.1108/09578230710829928.

10. Callender, C.C. , 2019. Race and race equality: whiteness in initial teacher education. In: P.Miller and C.Callender, eds. Race, education and educational leadership: an integrated analysis . London: Bloomsbury.

11. Camacho Felix, S. , 2019. Addressing attainment gaps: BAME students experiences and recommendations for LSE . London School of Economics: Learning and Teaching Centre.

12. Castles, S. , 1996. The racism of globalisation. In: E.Vasta and S.Castles, eds. The teeth are smiling: the persistence of racism in multicultural Australia . Sydney, Australia: Allen \& Unwin.

13. Christensen, J. and Rog, H.E. , 2008. Talent management: A strategy for improving employee recruitment, retention and engagement within hospitality organizations. International journal of contemporary hospitality management, 20 (7), 743-757. doi:10.1108/09596110810899086. 
14. Connolly, P. , 1996. Seen but never heard: rethinking approached to researching racism and young children. Discourse , 17 (2), 171-183.

15. CRER/Respectme, n.d.. Addressing inclusion: effectively challenging racism in schools . Edinburgh: The Scottish Government.

16. Curtis, P. , 2008. Education: black caribbean children held back by institutional racism in schools, Guardian, September.

17. Darling-Hammond, L. , et al., 2007. Preparing school leaders for a changing world: lessons from exemplary leadership development programs . Stanford, CA: Stanford University, Stanford Educational Leadership Institute.

18. Demie, F. , 2003. Raising the Achievement of Black Caribbean pupils in British schools: unacknowledged problems and challenges for policy makers. London review of education , 1 (3), 229-248. doi:10.1080/1474846032000146785.

19. Demie, F. and Mclean, C. , 2017. Black caribbean underachievement in schools in England. London: Research and Statistics Unit, Lambeth Education and Learning.

20. Department for Education , 2016. Permanent and fixed-period exclusions in England: 2014 to 2015 , DfE SFR26/2016.

21. Department for Education , 2020. School workforce in England: november 2018. Available from: https://www.ethnicity-factsfigures.service.gov.uk/workforce-and-business/workforce-diversity/schoolteacher-workforce/latest [Accessed March 2020].

22. Department of Education and Training, n.d.. Racism no way, fact sheets . Available from: www.racismnoway.com.au/library/understanding/indexWhat.html [Accessed February 2020]

23. Dismantling Racism, 2019. Anti-racist organizational development, catholic volunteer network. Available from: https://catholicvolunteernetwork.org/wpcontent/uploads/2019/02/Anti-Racist-Organizational-Development-andAssesment-Tool-Western-States-Center.pdf

24. Equality Challenge Unit, 2011. The experience of Black and minority ethnic staff in higher education in England. London: Equality Challenge Unit.

25. Fullan, M. , 1999. Change forces: the sequel . London: Taylor \& Francis/Falmer.

26. Fullan, M. , 2009. The challenge of change: start school improvement now. Thousand Oaks, CA: Corwin Press.

27. Gillborn, D. , 1995. Racism and anti-racism in real schools . Buckingham, UK: Open University Press.

28. Gillborn, D. , 1996. Student roles and perspectives in antiracist education: A crisis of white ethnicity. British educational research journal , 22 (2), 165179. doi:10.1080/0141192960220202.

29. Gillborn, D. and Youdell, D. , 2000. Rationing education: policy, practice, reform and equity. Buckingham: Open University Press.

30. Gooden, M.A., 2012. What does racism have to do with leadership? Countering the idea of color-blind leadership: a reflection on race and the growing pressures of the urban principalship. Educational foundations , 67-84. Winter-Spring. 
31. Greene, M.P. , 2007. Beyond diversity and multiculturalism: towards the development of anti-racist institutions and leaders. Journal for non-profit management, 9-17.

32. GSecEd, 2015. Improving diversity among leaders . Available from: www.seced.co.uk/best-practice/improvingdiversity-amongleaders [Accessed March 2020].

33. Haque, Z. and Elliott, S. , 2016. Visible and invisible barriers: the impact of racism on BME teachers . London: National Education Union/Runnymede Trust.

34. Henze, R.C. , 2000. Leading for diversity: how school leaders achieve racial and ethnic harmony. University of California: Center for Research on Education, Diversity and Excellence, Research Brief 6.

35. Hollinsworth, D. , 1998. Race and racism in Australia . 2nd ed. Katoomba, Australia: Social Science Press.

36. Lancashire County Council , 2007. Guidelines and procedures for dealing with and reporting racist incidents in schools . Lancs: Directorate for Children and Young People, School Effectiveness Service.

37. Lander, V. , 2011. Race, culture and all that: an exploration of the perspectives of White secondary student teachers about race equality issues in their initial teacher education. British educational research journal , 43 (1), 29-48.

38. Lewis, R.E. and Heckman, R.J. , 2006. Talent management: a critical review. Human resources management review , 16 (2), 139-154. doi:10.1016/j.hrmr.2006.03.001.

39. Macpherson, W. , 1999. The Stephen Lawrence inquiry . London, The Stationery Office, CM 4262-I.

40. Maylor, U. , et al., 2009. Black childrens' achievement programme evaluation Report [Report commissioned by the DCSF] . London, DCSF.

41. McMahon, B. , 2007. Educational administrators' conceptions of whiteness, anti-racism and social justice. Journal of educational administration , 45 (6), 684-696. doi:10.1108/09578230710829874.

42. McNamara, O. , et al., 2009. The leadership aspirations and careers of Black and minority ethnic teachers . London: NASUWT and National College for Leadership of Schools and Children's Services.

43. Miller, P. , 2012. Editorial: educational leadership in the caribbean \& beyond. Journal of the university college of the Cayman Islands , 6, 9-10.

44. Miller, P., 2016. 'White sanction', institutional, group and individual interaction in the promotion and progression of black and minority ethnic academics and teachers in England. Power \& education , 8 (3), 205-221. doi: $10.1177 / 1757743816672880$.

45. Miller, P. , 2018. Race discrimination, cultural inequality, and the politics of knowledge in England. University of Northumbria, British Educational Research Association - Annual Conference Keynote, 11 - 13 September.

46. Miller, P. , 2019a. Race and ethnicity in educational leadership. In: T.Bush, L.Bell, and D.Middlewood, eds. Principles of educational leadership \& management. 3rd ed. London: SAGE. 
47. Miller, P. , 2019b. 'Tackling' race inequality in school leadership: positive actions in BAME teacher progression - evidence from three English schools. Educational management administration \& leadership , 174114321987309. OnlineFirst. doi:10.1177/1741143219873098.

48. Miller, P. , 2019c. Race discrimination, cultural inequality, and the politics of knowledge in England. In: R.Papa, ed. Springer handbook on promoting social justice in education. Netherlands: Springer.

49. Miller, P. , 2020. Race/ethnicity, identity and co-identification in higher education: are we there yet? Conference Keynote: University of Greenwich's SHIFT Conference, January London, UK.

50. Mitgang, L. and Gill, J. , 2012. The making of the principal: five lessons in leadership training. Perspective. Wallace Foundation.

51. NEA Policy Brief, 2008. Changing role of school leadership . Available from: http://www.nea.org/assets/docs/PB09_Leadership08.pdf

52. Pells, R., 2017. Black and minority teachers face 'inherent racism' in UK schools, report warns. The Independent Online. Available from: https://www.independent.co.uk/news/education/education-news/bmeteachers-racism-uk-schools-black-minority-ethnic-education-nasuwtrunneymede-trust-a7827131.html

53. Pettman, J. , 1992. Living in the margins: racism, sexism and feminism in Australia . Sydney, Australia: Allen and Unwin.

54. Phillips, T. , 2016. Race \& faith: the deafening silence . London, Civitas: Institute for the Study of Civil Society. Available from: http://www.civitas.org.uk/content/files/Race-andFaith.pdf [Accessed April 2020].

55. Raby, R. , 2004. There's no racism at my school, it's just joking around': ramifications for anti-racist education. Race, ethnicity and education , 7 (4), 367-383. doi:10.1080/1361332042000303388.

56. Ryan, J. , 2012. Struggling for inclusion educational leadership in a Neoliberal World: issues in the research, theory, policy, and practice of urban education . Charlotte, NC: Information Age Publishers.

57. Soyei, S., 2011. The barriers to challenging racism and promoting race equality in England's schools. Tyne \& Wear: Show Racism the Red Card.

58. Strand, S. , 2012. The White British-Black caribbean achievement gap: tests, tiers and teacher expectations. British educational research journal , 38 (1), 75-101. doi:10.1080/01411926.2010.526702.

59. Strand, S., 2015. Ethnicity, deprivation and educational achievement at age 16 in England: trends over time . University of Oxford. Available from: https://www.gov.uk/government/uploads/system/uploads/attachment_dat a/file/439867/RR439B-

Ethnic minorities and attainment the effects of poverty annex.pdf.pdf

60. Suarez, K. , 2018. The role of senior leaders in building a race equity culture. Boston: The Bridgespan Group.

61. Theoharis, G. and Brooks, J.S. , Eds., 2012. What every principal needs to know to create equitable and excellent schools. New York: Teachers College Press. 
62. Whitmire, T. , 2012. Strengthening school leadership . Portland, Oregon: Stand for Children Leadership Center, June.

63. Yamato, G. , 1990. Something about the subject makes it hard to name. In: G.Anzuldua, ed. Making face, making soul . San Francisco: Aunt Lute Foundation Books. 